\title{
The changing face of infectious endocarditis
}

I N THIS ISSUE OF CARDIOLOGY IN THE YOUNG, THE reader will find an article concerned with infectious endocarditis. ${ }^{1}$ The article show that infectious endocarditis continues to be an important disease in childhood. Important because of morbidity and mortality, and because of questions about the disease itself. Is there a real increase in incidence, have presentation and diagnostic criteria changed, who should receive prophylaxis and does it really matter, and when is surgical intervention indicated?

There is good evidence that infectious endocarditis is indeed becoming more common in children. ${ }^{2-4}$ In a study from the Children's Hospital of Pittsburgh based on experience from three decades, ${ }^{5}$ the diagnosis was made twice as often in the second decade than the first, and three times as often in the third. The percentage of hospital admissions for infectious endocarditis increased from $0.16 \%$ in the first decade to $0.33 \%$ in the last. The increase has been postulated to be due, in part, to a larger pool of children with congenital heart disease because of successful surgical repair and to an increasing number of invasive procedures. The pool of susceptible children is certainly larger, yet two-fifths of the children in the Pittsburgh experience had never undergone surgery. In the same study, only onetenth of the children had undergone cardiac catheterization, surgery or extracorporeal membrane oxygenation support in close enough proximity to the onset of disease to be considered likely to be related. Another study reported similar findings. ${ }^{6}$

The so-called "classical" findings of infectious endocarditis, for example Osler's nodes and Roth spots, are quite rare. The diagnosis is usually straight-forward, and depends upon obtaining at least one positive blood culture in a febrile child, who usually has pre-existing heart disease. In the paper from India ${ }^{1}$, infectious clubbing was common, occurring in 14 of 43 cases (an additional 7 cyanotic patients had clubbing). Each had had fever for over 6 weeks, so the long delay in diagno- sis may account for the high incidence of clubbing. One fourth of the Indian children had rheumatic heart disease ${ }^{1}$ doubtless reflecting the much higher prevalence of rheumatic heart disease in developing countries. The incidence of positive blood cultures was under $40 \%$ in the Indian series. The reasons for this are not apparent.

Some authors have described a change in cardiac substrate over the years, especially an increase in mitral valvar prolapse 7,8 and surgically altered congenital heart disease. ${ }^{2}$ This was not confirmed in the current review or in the Pittsburgh experience previously reported in this journal ${ }^{5}$. Rather, ventricular septal defect, obstruction of the left ventricular outflow tract, and cyanotic lesions such as tetralogy of Fallot and tricuspid atresia are by far the most common underlying lesions in children with infectious endocarditis.

The infecting organism has also been thought to be changing, with more "unusual" organisms, ${ }^{8}$ but staphylococcus and streptococcus continue to be the infecting organism in a large majority of cases.

Although almost always advocated, the usefulness of the administration of antibiotics before and after dental and surgical procedures in preventing infectious endocarditis has not been conclusively demonstrated. The early work from Guntheroth,? showing that the chewing of food resulted in bacteremia is a case in point, and no history of recent dental or surgical procedures could be elicited in the majority of cases in his and other ${ }^{6}$ series. Children may still develop infectious endocarditis in spite of standard prophylaxis. A study from Holland ${ }^{6}$ suggested that even strict adherence to prophylaxis in individuals at risk for endocarditis in native valves might do little substantially to decrease the number of cases of endocarditis in the community. Nonetheless, the policy of prophylaxis against endocarditis has come to be accepted.

Does the surgical repair of a cardiac defect reduce or eliminate the risk of infectious endocarditis? It depends on the defect. Current recommendations do not mandate prophylaxis after repair of ventric- 
ular septal defect, ${ }^{10}$ but there continues to be some controversy on this point. In the Pittsburgh series 5 there were 15 cases with a simple ventricular septal defect. Ten were small and unrepaired, and each of the five who had undergone repair had a residual defect. There have been no other cases of infectious endocarditis in the 527 children undergoing repair of a ventricular septal defect in our institution (unpublished data). This suggests that complete elimination of a left-to-right shunt at ventricular level makes infectious endocarditis at least very unlikely following repair. We have also failed to discover any cases of endocarditis in children with an isolated patent arterial duct. The policy in our institution is to repair a patent duct when diagnosed, so the prevalence of patent unoperated duct is low beyond early infancy, but no case of endocarditis has been found in even a closed duct, for which prophylaxis is not currently advised. Whether or not a "silent" patent duct (Doppler evidence of a tiny shunt but no murmur) requires prophylaxis is still controversial.

Repair of obstruction within the left ventricular outflow tract has been reported to increase, the risk of infectious endocarditis, ${ }^{11}$ but longer follow-up in the same cohort of patients suggested that severity of aortic stenosis, not surgical status, was the important risk factor. ${ }^{12}$ Risk continues after repair of complex lesions such as tetralogy of Fallot or atrioventricular septal defect. Whether children who have had an arterial switch procedure, or the Fontan operation, are at risk is not definitely known.

A high incidence of suspicion in a febrile child at risk, (one with unoperated congenital heart disease other than an atrial septal defect, or one with repaired congenital heart disease other than a simple septal defect with no residual left-to-right shunt) is probably the most important factor in early diagnosis. Early diagnosis and appropriate therapy are doubtless important in minimizing the chance of cardiovascular damage. Cardiac damage usually takes the form of valvar regurgitation, either new or increased in severity. Many reports of infectious endocarditis cite "new or changing murmurs" in the clinical presentation. Surely we can be more precise. The only new murmur helpful in diagnosing cardiac involvement in a febrile child is one of mitral or aortic regurgitation or, rarely, tricuspid regurgitation, and, exceptionally, pulmonary regurgitation. Congestive heart failure is usually due to severe regurgitation, or occasionally to myocardial damage or dysfunction from an abscess, aneurysm, or coronary embolus. Vascular damage takes the form of either formation of an aneurysm or arterial occlusion from an embolus. Surgical intervention depends upon the severity of the damage. The timing of intervention must be decided on an individual basis, with urgent intervention if infection cannot be controlled, or if the hemodynamic abnormality cannot be compensated. The indications for surgical removal of an intracardiac or intravascular thrombus are still poorly defined.

Mortality has surely declined, with a fall from $36 \%$ to $8 \%$ over a 30 year period in one large series. ${ }^{5}$ Earlier diagnosis, more effective antibiotic coverage, and appropriate surgical intervention are doubtless important factors in the improved outlook of infectious endocarditis in childhood.

James R. Zuberbuhler Children's Hospital, Pittsburgh, USA

\section{References}

1. Sharma M, Saxena A. Kothari SS, Reddy SCB, Venugopal P, Wasir HS. Infectious endocarditis in children: changing pattern in a developing country. Cardiol Young 1997

2. Johnson DH, Rosenthal A, Nadas AS. A forty-year review of bacterial endocarditis in infancy and childhood. Circulation 1975; 51: 581-588.

3. VanHare GF, Ben-Shachar G, Liebman J, Boxerbaum B, Riemenschneider TA. Infective endocarditis in infants and children during the past 10 years: A decade of change. Am Heart J 1984; 107: 1235-1240.

4. Parras F, Bouza E, Romero J, Buzón, Quero m, Brito J, Vellibre D. Infectious endocarditis in children. Pediatr Cardiol 1990; 11 : 77-81.

5. Zuberbuhler JR, Neches WH, Park SC. Infectious endocarditis- an experience spanning three decades. Cardiol Young 1994; 4: 244-251.

6. Van der Meer JTM, Van Wijk W, Thompson J, Vanderbroucke JP, Valkenburg HA, Michel MF, Efficacy of antibiotic prophylaxis for prevention of native-value endocarditis. Lancet 1992; 339: 135-139.

7. MacMahon SW, Hickey AJ, Wilcken EL, Wittes JT, Feneley MP, Hickie JB. Risk of infective endocarditis in mitral valve prolapse with and without precordial systolic murmurs.AM J Cardiol 1986; 58: 105-109.

8. Awadallah SM, Kavey REW, Byrum CJ, Smith FC, Kveselis DA, Blackman MS. The changing pattern of infective endocarditis in childhood. Am J Cardiol 1991; 68: 90-94.

9. Gutheroth WG. How important are dental procedures as a cause of infective endocarditis? Am J Cardiol 1984; 54: 797-801.

10. Dajani AS, Bisno AI, Chung, KJ, Durack, DT, Freed M, Gerber MA, Karchmer AW, Millard HD, Rahimtoola S, Shulman ST, Watanakunakorn C, Taubert KA. Prevention of bacterial endocarditis. JAMA 1990; 264: 2919-2922.

11. Gersony WM, Hayes CJ. Bacterial endocarditis in patients with pulmonary stenosis, aortic stenosis and ventricular septal defect. Circulation 1977; 56(Suppl I): I 84-I 87.

12. Gersony WM, Hayes CJ, Driscoll DJ, Keane JF, Kidd L, O'Fallon WM, Pieroni DR, Wolfe RR, Weidman WH. Bacterial endocarditis in patients with aortic stenosis, pulmonary stenosis, or ventricular septal defect. Circulation 1993; 87(Suppl I): I 121 - I 126. 